\title{
"n
}

\section{SIGNIFICADOS COMPARTIDOS Y TOMA DE DECISIONES: EL MITO $Y$ LA HISTORIA COMO ELEMENTOS SIMBÓLICOS INCIDENTES EN UNA EMPRESA FAMILIAR COLOMBIANA DE TRANSPORTE TERRESTRE*}

\author{
Maximiliano Gastón Ballesteros"* \\ David Alejandro Restrepo Díaz
}

doi:10.11144/Javeriana.cao.30-55.sctd. Este artículo es producto de la investigación de Comprender las incidencias de los significados compartidos en la toma de decisiones gerenciales al interior de una empresa familiar colombiana de transporte terrestre. El artículo se recibió el 25/09/2017 y se aprobó el 25/11/2017. Sugerencia de citación: Ballesteros, M. G., y Restrepo, D. A. (2017). Significados compartidos y toma de decisiones: el mito y la historia como elementos simbólicos incidentes en una empresa familiar colombiana de transporte terrestre. Cuadernos de Administración, 30(55), 127-161. http:// dx.doi.org/10.11144/Javeriana.cao.30-55.sctd.

** Magister en Ciencias de la Administración de la Universidad EAFIT, Medellín, Colombia, 2017. Profesor de la Universidad EAFIT, Medellín, Colombia.

Correo electrónico: mballles4@eafit.edu.co

*** Magister en Estudios Humanísticos de la Universidad EAFIT, Medellín, Colombia, 2015. Profesor auxiliar del departamento de mercadeo de la Universidad EAFIT, Medellín, Colombia.

Correo electrónico: drestrepo@eafit.edu.co 


\section{Significados compartidos \\ y toma de decisiones: el mito y la historia como elementos simbólicos incidentes en una empresa familiar colombiana de transporte terrestre}

Shared meanings and decision-making: The myth and the history as incident symbolic elements in a Colombian ground transportation family-owned company

\section{ResUmen}

La toma de decisiones en organizaciones familiares ha sido un tema importante en el estudio de la propiedad empresarial familiar, sin embargo, las investigaciones no han profundizado en las dimensiones socioculturales. Este estudio abordó la organización empresarial familiar desde la perspectiva de los significados compartidos planteados por March (mitos, símbolos, rituales e historias). En este sentido, se implementó el método biográfico de Vieytes para comprender cómo inciden los significados compartidos en la toma de decisiones gerenciales al interior de una empresa familiar colombiana de transporte terrestre. Los resultados evidenciaron que el mito del fundador juega un papel central en la toma de decisiones de la dirección y convierte el proceso en una dinámica organizacional ritualizada.

Palabras clave: toma de decisiones, empresa familiar, significados compartidos, mito, historia.

Códigos JEL: D7, M14, Z13

\section{ABSTRACT}

Decision-making in family organizations has been an important issue in the study of family business property, although the studies in the area do not display aspects such as sociocultural dimensions. This study had an approach of the family business organization from the shared meanings suggested by March (myths, symbols, rituals, stories), through the biographical methodology of Vieytes to understand how shared meanings affects in the management decision making in a Colombian family-runned transportation company. From the research, it was evident that the myth of the founder plays a central role in the decision-making of the director's board, turning the process into a ritualized organizational dynamic.

Keywords: Decision-making, family business, shared-meaning, myth, history. JEL Classification: D7, M14, Z13

\section{Significados}

compartilhados e tomada de decisões: o mito e a história como elementos simbólicos incidentes numa empresa familiar colombiana de transporte terrestre

\section{RESUMO}

A tomada de decisões em organizações familiares tem sido um tema importante no estudo da propriedade empresarial familiar; contudo, as pesquisas não têm aprofundado nas dimensões socioculturais. Este estudo abordou a organização empresarial familiar sob a perspectiva dos significados compartilhados propostos por March (mitos, símbolos, rituais e histórias). Nesse sentido, aplicou-se o método biográfico de Vieytes para compreender como os significados compartilhados incidem na tomada de decisões gerenciais no interior de uma empresa familiar colombiana de transporte terrestre. Os resultados evidenciaram que o mito do fundador desempenha um papel central na tomada de decisões da direção e converte o processo numa dinâmica organizacional ritualizada.

Palavras chave: tomada de decisões, empresa familiar, significados compartilhados, mito, história. Classificação JEL: D7, M14, Z13 


\section{Introducción}

En estudios sobre organizaciones empresariales a nivel internacional se identificó que entre 70 y $80 \%$ de las empresas que se forman, provienen del contexto familiar. Por su naturaleza, las empresas familiares suelen ser dirigidas por sus dueños, tienen una tendencia a la centralización en la toma de decisiones y están atravesadas con la interferencia familiar (Molina, Botero y Montoya, 2016). Esto trae como consecuencia problemas de índole financiero y comercial que afectan tanto la parte empresarial como la familiar. Las investigaciones de Lozano y Urbano (2008), Sandoval y Guerrero (2010) y Solano (2010) argumentan que el problema principal radica en los procesos concernientes a la toma de decisiones sobre aspectos fundamentales para la empresa, como inversión, exportación y endeudamiento; sucesiones y elección de cargos directivos. En cuanto a la metodología, Ginebra (2001) destaca que la mayoría de estudios sobre empresas familiares son cuantitativos sobre temas como indicadores de eficiencia, producción, saneamiento de finanzas y gestión de recursos. Mientras que los aspectos cualitativos como las dimensiones socioculturales de los significados compartidos, las cuales inciden en la decisión, han recibido menos atención (Benavides, Guzmán y Quintana, 2011).

Las dimensiones socioculturales que influyen en la sucesión, gobierno y demás aspectos de la administración corporativa fueron estudiadas por Dyer (1988) en donde reportó el rol del fundador como central para la creación de la cultura organizacional. Sin embargo, los estudios posteriores no han logrado profundizar en los mecanismos más efectivos para transmitir la cultura en las sucesivas generaciones, afectar las decisiones estratégicas y reconocer la importancia de las particularidades de las empresas, en su éxito intergeneracional (Benavides et ál., 2011). En relación con lo anterior, se puede establecer que el estudio de las dimensiones socioculturales es limitado porque: 1) los avances en la materia no han dado para profundizar en dichas realidades, 2) medir y evaluar aspectos socioculturales no es fácil al desarrollar métodos cuantitativos, y 3 ) el reconocimiento del papel que tienen las dimensiones socioculturales dentro del proceso de toma de decisiones es reciente. Sin embargo, la tendencia dominante de los estudios organizacionales es contraria a la relación entre significados compartidos y organización familiar. Así fue señalado por Smircich (1983):

Las perspectivas cognitiva, simbólica, estructural y psicodinámica sobre organización y cultura tienen focos de interés distintos, que llevan a los académicos que sostienen estas perspectivas a formular preguntas diferentes y a seguir su programa de investigación de maneras distintas. Sin embargo, subyace en estas diferencias 
un modo de pensamiento que aleja a estas [perspectivas] de las que conciben la cultura como una variable. (Smircich, 1983, p. 28)

Según la autora, se debe estudiar la cultura como un artefacto epistemológico para desarrollar investigaciones sobre la organización como fenómeno social. Por su parte, Chanlat (2002, p. 51) denominó los fenómenos sociales como "aspectos simbólicos de la vida colectiva" e insistió en estudiarlos puesto que "pueden ser observados e interpretados como datos". De tal forma, se justifica la realización de estudios centrados en organizaciones familiares, que aborden la incidencia de las dimensiones socioculturales en la toma de decisiones de los significados compartidos dentro de las organizaciones empresariales.

En relación con lo anterior, se identificó la teoría de la ambigüedad y la interpretación de March (1994) para comprender cómo los significados compartidos inciden en la toma de decisiones gerenciales al interior de una empresa familiar colombiana de transporte terrestre. Dado que la empresa y la familia se encuentran en constante convivencia y se influyen mutuamente - hasta el punto en que los integrantes de la familia intercambian roles y de manera concisa llevan aspectos funcionales, emocionales y simbólicos de la familia hacia la empresa (Bastar, 2013) - es una prioridad proponer investigaciones que consideren dimensiones humanas y, particularmente, necesidades emocionales en los procesos de toma de decisiones, en los estudios organizacionales de la empresa familiar.

Etkin (2006) propone que los procesos mentales, las creencias y los valores de los individuos hacen presente la "estrategia de la ilusión", como aquello que moviliza a los directivos hacia el establecimiento de mitos y leyendas, como articuladores en los procesos de toma de decisión que dan sentido al quehacer en el día a día dentro de la empresa (p. 75). Por consiguiente, el presente trabajo se inscribe en la corriente estructuralista de March y busca evidenciar el valor de los estudios cualitativos en las organizaciones y fundamentar el rol del fundador dentro de la estructuración de los principios de la empresa. Esto para dar cuenta de la diversidad de aspectos simbólicos que se mueven al interior de las empresas familiares (Dyer, 1988; Stewart, 2012).

Para ello se elaboró un marco teórico sobre los enfoques de estudio de la empresa familiar, la toma de decisiones según March (1994) y los significados compartidos como elementos incidentes en el proceso de decisión. En los diferentes enfoques abordados se siguieron autores de postura cualitativo-constructivista. En segundo lugar, se explica 
la metodología cualitativa aplicada y el proceso que dio lugar a la interpretación de los resultados. Y, por último, se presenta la discusión y las conclusiones finales.

\section{Marco teórico}

Las investigaciones en las empresas familiares no solo han aumentado significativamente en las dos últimas décadas, sino que han tenido un enfoque principalmente cuantitativo (Benavides et ál., 2011). Uno de los retos más importantes en el área consiste en entender cómo y por qué las empresas familiares se comportan y obtienen resultados diferentes a otro tipo de organizaciones al estudiar los procesos dentro de los gobiernos corporativos (Chua, Chrisman y Steier, 2003). La toma de decisiones se evidencia cómo aspecto central en cada fase del ciclo de vida organizacional sea en relación con el gobierno corporativo, la profesionalización, la dirección financiera, la dinámica familiar interpersonal, las prácticas de recursos humanos, entre otras de gran importancia para el área (Benavides et ál., 2011; San Martín Reyna y Durán Encalada, 2016).

Al seguir los estudios que se enfocaron sobre la toma de decisiones en las empresas familiares, se evidenció que las investigaciones más destacadas no desarrollaron metodologías de corte cualitativo para abordar las dimensiones socioculturales y su incidencia en el proceso de toma de decisión. Sin embargo, tanto Garmendia (1988) como Dyer (1988) señalaron que los estudios de las dimensiones socioculturales aportan conceptos fundamentales para entender los procesos decisión y estructuración dentro de las organizaciones empresariales familiares.

A pesar de la preponderancia de estudios de tipo cuantitativo, algunas investigaciones se interesan directa o indirectamente por algunas dimensiones socioculturales; tal es el caso de Sundaramurthy (2008), que aborda la confianza generada por el vínculo familiar y la orientación de decisiones empresariales; Björnberg y Nicholson (2012), que trabajaron la relación entre la dimensión emocional del dirigente empresarial y el uso funcional de la propiedad; Chirico, Nordqvist, Colombo y Mollona (2012), quienes aplicaron una técnica de simulación de método psicodinámico que interpretó cómo el paternalismo afecta las capacidades de la empresa familiar e influye en la creación de valores corporativos; Koropp, Kellermann, Grichnik y Stanley (2014), que adecuan a la empresa familiar alemana la teoría del comportamiento planificado en la toma de decisiones financieras y demuestran que el proceso está influenciado por normas, actitudes, controles y comportamientos evidenciados en el grupo familiar. $Y$ en años recientes un enfoque novedoso ha desarrollado componentes emocionales como lo evidencian 
Arenas y Rico (2014) que señalan que la influencia de la familia sobre la propiedad y los roles ocupacionales, potencian y/o debilitan la organización, con lo cual repercuten en decisiones desacertadas. Y, por último, Lizaur (2014) agrega que:

Los factores culturales, especialmente las formas de herencia, inciden en la sustentabilidad de las empresas familiares y de las élites empresariales a lo largo de las generaciones. No seguir las normas culturales de herencia, género y jerarquía familiares genera conflictos que, a su vez, inciden en el buen desempeño de las empresas, condición necesaria para crecer y adentrarse en los grandes mercados y para la sustentabilidad familiar. (Lizaur, 2014, p. 195)

\section{Enfoques de estudio de la empresa familiar}

Es importante aclarar que el término tradicional de empresa familiar es limitado, pues no logra abarcar un conjunto complejo de realidades organizacionales. Por ello se optó por abordar su entendimiento desde la perspectiva de un enfoque constructivista y no uno de corte funcionalista, como ha prevalecido en buena parte de la literatura. En este sentido, los negocios familiares se consideran como una construcción organizacional difusa, dinámica y estructurada (De la Rosa et ál., 2009). Este enfoque permite profundizar en estudios interpretativos y usar metodologías novedosas para establecer un nivel de aplicabilidad mayor sobre los conceptos. El problema real consiste en el cómo se limita la comprensión de la realidad empresarial dentro de la familiar, y viceversa, lo cual afecta la comprensión de los fenómenos estudiados. En este sentido, se encontraron tres enfoques sobre el estudio de la empresa familiar que se muestran a continuación.

\section{COMO UNIDAD FUNCIONAL DE UN TIPO DE NEGOCIO}

Hollander y Elman (1988) conciben la empresa familiar en dos frentes: el racional como organización productiva, y el no racional, como organización familiar. Al separarlos y plantear una existencia paralela, afirmaron relaciones funcionales construidas en el tiempo. Por el mismo camino, Kaslow (1993) evidenció que empresa y familia se influyen y moldean la una a la otra, pero se mantienen en planos independientes. Mientras tanto, Casillas, Díaz y Vásquez (2005) definieron que el trabajo de algunos miembros de la familia propietaria, se desempeña a través de funciones ejecutivas, que el gerente controla como miembro de los propietarios. 
De modo contrario a lo anterior, Kremer (2006) consideró que la empresa familiar puede ser tanto pequeña como mediana e, incluso, puede ser una empresa multinacional. Por consiguiente, Carrasco y Rubio (2007) definieron la pyme familiar como una entidad caracterizada por ser propiedad de los miembros de un mismo grupo familiar o presentar intervención de miembros de una misma familia en la dirección del negocio. En contra de este argumento, Trevinyo-Rodríguez (2010) argumentó que la definición de empresa familiar es intrínseca y que no se determina por asuntos exteriores, para cuyo efecto justifica que el adjetivo familiar cumple su papel en la definición del negocio-empresa y que empresa familiar quiere decir simplemente empresa más familia.

\section{COMO UNIDAD OPERATIVA DE UNA ESTRUCTURA COLABORATIVA}

Frente a la pregunta sobre la composición accionaria de las empresas familiares, Casillas, Díaz y Vásquez (2005) establecieron que el porcentaje de participación de la familia sobre el capital total de la empresa o el control de un familiar sobre la misma determina otro modelo de calificación. Así, Cruz, Ramírez, Lozano, Zebadúa, Sánchez, Molina y Velasco (2013) señalaron que la empresa familiar en lo fundamental es operada por miembros de una familia que se encuentran en diferentes niveles, los cuales van desde la dirección hasta los comerciales y operativos. González, Hernández y Rodríguez (2013) coincidieron sobre lo anterior y agregaron que el capital y la gestión del negocio se pueden encontrar en manos de una o más familias. Estas discusiones señalan una visión del concepto de empresa familiar que va más allá de dos instituciones paralelas y llega a la integración de dinámicas mixtas con un propósito operativo y estructural dentro de la empresa.

Por su parte, Bastar (2013) definió la empresa familiar como aquella unidad que persigue fines netamente financieros (utilidades y recursos materiales), de modo que dichos recursos se integren al patrimonio del grupo familiar con el tiempo. En este sentido, Bastar concuerda también en señalar que la dirección y la operación de la organización están siempre por lo menos en manos de dos miembros familiares y que existe una centralización en la toma de decisiones organizacionales que será relevada por nuevas generaciones del grupo familiar originario (Gentilin y Gonzales-Miranda, 2017).

\section{COMO PROLONGACIÓN DE LA FAMILIA EN EL USO DE UN RECURSO}

Por último, se define una línea completamente diferente a la funcional y la estructural. En ella, la relación entre familia y empresa se articula por medio del deseo de mantener, a lo largo del tiempo, una participación en el desarrollo de la empresa (Casillas 
et ál., 2005). En este grupo se encuentran las empresas intergeneracionales y las familias copropietarias que intervienen en los asuntos empresariales y que hacen que las dinámicas de control y poder de los descendientes directos del fundador tengan un ejercicio transversal y longitudinal en el entendimiento del negocio y de la gestión de la propiedad de la empresa. De este modo, se trata de un enfoque sociológico que involucra dinámicas funcionales, operativas, emocionales y simbólicas (Etkin, 2006; Orozco y Rentería, 2012). Por consiguiente, se visualiza a la empresa familiar como un ente sociocultural transcendente en la sociedad.

Los autores Cisneros, Ramírez y Hernández (2011) en sus aportes académicos denotan que al existir una realidad empresarial y una familiar, es de gran necesidad interpretar y analizar la configuración del sistema de valores y creencias compartidas, los cuales integran la conformación organizacional para el mejor cumplimiento de los objetivos y el buen funcionamiento empresarial. En el mismo sentido, De la Garza, Medina, Cheín, Jiménez, Ayup, y Díaz (2011) argumentaron que la influencia del fundador en la situación presente de la organización, es decisiva y reconocida tanto por la familia como por los empleados y sigue transmitiendo su visión a través de las generaciones. Es por esto que, Martín y Martínez (2013) explicaron que al ser una combinatoria de propiedad y familia, la empresa familiar contiene una gran carga emocional que trae como resultado, un conjunto de conflictos por resolver. Motivo por el cual es importante buscar metodologías que favorezcan el equilibrio entre la parte operativa, la propiedad sobre la empresa, y la gestión familiar.

En la presente investigación se sigue el enfoque cultural descrito. En este sentido, la razón central estuvo sustentada en la manera en que el fundador proyectó la organización como medio para dejar un patrimonio socioeconómico para generaciones venideras. Por consiguiente, la unidad de estudio fue indagada en sus dimensiones simbólicas para comprender cómo los significados compartidos inciden en la toma de decisiones gerenciales al interior de una empresa familiar colombiana de transporte terrestre.

TEORÍA de LA AMBIGÜEdAd y TOMA DE DECISIÓN SEGÚN JAMES MARCH

Según March (1994), la toma de decisiones debe buscarse más allá de una racionalidad absoluta o limitada, en el conjunto ontológico de dimensiones que modifican e influyen la decisión final. March desagregó los mecanismos del proceso en: 1) realidad, o el momento justo en que se va a tomar alguna decisión; 2) causalidad, o las causas de la 
decisión y los efectos de tomarla, y 3) intencionalidad, o la comprensión de la finalidad del tomador de la decisión y la visualización de escenarios posibles para estructurarla. De acuerdo con el autor, se trata de elementos cambiantes que hacen las decisiones ambiguas $y$, por consiguiente, genera faltas de claridad.

En este sentido, ninguna decisión se toma de manera totalmente racional, ni existen decisiones con racionalidad limitada, sino que las decisiones son tomadas mediante una sucesión de pasos que no siguen un orden lógico, sino ontológico, entre los cuales se encuentra la construcción de los significados compartidos, que son los que se deben tener en cuenta para comprender los procesos de decisión y los elementos, tales como símbolos, mitos, historias y rituales (March, 1994).

Desde la teoría organizacional, Chandler (1962) argumentó como los sistemas socioculturales están determinando las organizaciones a través de procesos históricos internos y externos, que se entrecruzan para dar explicación a los orígenes y los valores institucionales. Es así como las organizaciones tienen significados compartidos (Heirs y Perhson, 1972), sistemas cognitivos y recuerdos (Argyris y Schön, 1978), y cosmovisiones y mitos (Schein, 1985), los cuales se constituyen como mecanismos e influenciadores para la interpretación de la realidad organizacional y la comprensión de su forma de operar. Smircich (1983) argumenta que las organizaciones deben ser analizadas principalmente en términos de sus aspectos expresivos y simbólicos para comprender su funcionamiento de manera integral.

La teoría práctica, instaurada por Clifford Geertz, señala que para analizar aquellos significados que se comparten en la cultura de manera inteligible se debe proceder con la interpretación por parte del investigador de segmentos remarcables de la realidad a través de la extracción de actos de comunicación, acciones y valores orientadores. Geertz (1973) denomina a este proceso descripción densa, el cual consiste en detallar con amplias descripciones los contextos geográficos y socioculturales que suscriben el estudio como una interpretación estructural y profunda de los actos sociales. De este modo, las descripciones se convierten en:

una multiplicidad de estructuras conceptuales complejas, muchas de las cuales están superpuestas o enlazadas entre sí, estructuras que son al mismo tiempo extrañas, irregulares, no explícitas, y a las cuales el etnógrafo debe ingeniarse de alguna manera, para captarlas primero y para explicarlas después. (Geertz, 1973, p. 24) 
En relación con el acto social, Geertz define los significados compartidos como:

Un sistema de símbolos creados por el hombre, compartidos, convencionales, y, por cierto, aprendidos, [que] suministran a los seres humanos un marco significativo dentro del cual pueden orientarse en sus relaciones recíprocas, en su relación con el mundo que los rodea, y en su relación consigo mismos. (Geertz, 1973, p. 214)

Esta interpretación de la cultura busca comprender los significados compartidos en las interacciones sociales, interpretados, en este caso, en el contexto de la organización familiar (Morgan, 1991). Así, lo cultural se relaciona con elementos simbólicos que aparecen en la historia de la empresa (Fajardo, 1969). Es así como “el grado de estabilidad y orden alcanzado por la organización a través del establecimiento y consolidación de dichos mitos, evidentes en rituales, normas, rutinas, comportamientos, y expresiones, debe permitir el logro de las metas de la organización" (García, 2005, p. 168).

Estudios más recientes contribuyen en el entendimiento de los procesos de toma de decisión desde la complejidad: Etkin (2006) señaló que el proceso decisorio no solo se fundamenta en aspectos racionales, sino en dinámicas culturales y simbólicas (mitos, historias, símbolos) que tienen una incidencia significativa en los procesos de decisión organizacional en los cuales el gerente tiene la decisión final. En la misma dirección, Pacheco (2015) argumentó que las organizaciones son complejas debido a la convivencia de dos mundos: "el mundo compuesto por lo material y cuantitativo (el de las "cosas") y el inframundo constituido por los significados y sentidos que los actores organizacionales le otorgan a "las cosas" (p. 20). Ambos mundos, están orientados al logro de los objetivos y a las decisiones que deben tomar los directivos. A continuación, se definen los conceptos centrales del conjunto de significados compartidos establecidos por March (1994) que inciden en la toma de decisiones.

\section{LOS SÍMBOLOS COMO CÓDIGOS DOMINANTES E INSTRUMENTALES}

Desde el enfoque de la antropología simbólica, Geertz (1973) señaló que los símbolos son susceptibles de interpretación por parte del investigador. Así, el símbolo es código cultural para descifrar valores y motivaciones profundas del sentido social. Según March, aparecen como “objetos, prácticas o signos que evocan algo más, por medio de la asociación, la similitud o la convención. Así, el símbolo es un puente que vincula la 
experiencia organizacional con sentimientos profundos o con definiciones abstractas de los dilemas humanos" (March, 1994, p. 45). Dentro del conjunto de símbolos, March resalta la vestimenta y el lenguaje como elementos de poder y estatus. Por último, Turner (1999) categoriza los símbolos como dominantes e instrumentales: el símbolo dominante es antiguo y prevalece en el tiempo, relacionado con normas y leyes que producen estímulos emocionales profundos, mientras que el instrumental es un medio para el fortalecimiento de los procesos ritualísticos (Turner, 1999, pp. 33-35).

\section{EL MITO COMO ELEMENTO FUNDADOR}

Desde la perspectiva de la antropología estructuralista, Lévi-Strauss (1987) señala que el mito y la historia no pueden estar separados en su comprensión, pues se instauran y aúnan en las dinámicas discursivas sociales. Para March (1994), el mito es un suceso o personaje, real o ficticio, que apela a la conciencia social por medio de la encarnación de ideales colectivos particulares y la expresión de las emociones más profundas de los grupos humanos. El mito emerge como explicación del mundo y sus realidades para articular la vida económica, social y política de los pueblos, al tiempo que proporciona un conjunto asimilable de comportamientos para los grupos. En ese sentido, Eliade (1994) coincide con Lévi-Strauss en que el mito se constituye en modelo histórico de personajes socialmente representativos, los cuales aparecen en una dimensión sagrada y hablan sobre los orígenes de una institución para explicar los roles y los valores paradigmáticos de la cultura.

\section{LA HISTORIA COMO MEMORIA COLECTIVA QUE ARTICULA CONFLICTOS SOCIALES}

Desde la perspectiva estructuralista, la historia es un fenómeno socio-histórico que explica cómo sucedieron las cosas y da razones del estado actual en que se encuentra una sociedad (Lévi-Strauss, 1987). En general, la historia se compone de un conjunto de relatos articulados que son elaboraciones explicativas del devenir de los pueblos (March, 1994). La historia adquiere muchas herramientas del mito para constituirse y organizarse, solo que tiene como componente articulador un conflicto que se encuentra presente en la memoria colectiva de un grupo de personas. Debido a ello, Dumézil sugirió que la historia se articula como parte del mito y que subsiste en componentes narrativos que se denominan "sagas, leyendas, cuentos folklóricos y épicas nacionales" (Dumézil, 2016, p. 20). 
LOS RITUALES INTEGRADOS COMO PROCESO SIMBÓLICO Y MÍTICO

Según Goffman (1956), los ritos conversacionales entre dos o más personas suceden como fenómenos dentro de escenarios micro-sociales cotidianos y particulares. Estos señalan la importancia de una estructura social y simbólica compartida entre quienes hablan una misma lengua. Goffman estudió el micro-acto de habla, tales como el saludo y las fórmulas de cortesía, como aspectos centrales de la comunicación. Por otra parte, Van Gennep (1960) denominó ritos de pasaje a los momentos de cambio social en que los integrantes de una sociedad específica modifican sus estatus económico, político y cultural, frente al resto del grupo, para integrarse a nuevos niveles jerárquicos y dar lugar a un posicionamiento diferente en el transcurso de la vida.

El momento ritualístico tiene un antes, un durante y un después, que se convierte en un proceso de prueba en el que el sujeto destruye su identidad previa y se integra a una nueva identidad colectiva, mediante la reelaboración de mitos e historias fundacionales. Los rituales toman una "serie de formas ceremoniales mediante las cuales se preservan las tradiciones y se mantienen los significados" (March, 1994, p. 45). Así, el rito es "un proceso de construcción social identitaria" (Barelli, 2012, p. 235).

\section{Metodología}

A partir de la construcción del marco teórico se reconoció que buena parte de los estudios en el área de las empresas familiares se han desarrollo siguiendo variables de corte cuantitativo que explican las correlaciones entre factores externos tales como la economía y la política, y factores internos tales como la sucesión y el gobierno corporativo, entre otros (Arenas y Rico, 2014; Benavides et ál., 2011; De la Rosa et ál., 2009). Sin embargo, los estudios de carácter cualitativo que abordan los procesos de toma de decisión al interior de las empresas familiares están por realizarse. Un estudio de carácter cualitativo no busca la representatividad estadística, sino establecer una serie de generalizaciones de tipo analíticas y teóricas y explicar cómo se hizo para lograr este proceso (Yin, 2009). Dyer (1988) realizó una investigación en 40 firmas familiares en Estados Unidos, donde investigó los diferentes tipos de cultura corporativa con sus ventajas y problemáticas, que, a su vez, estructuran procesos de cambio organizacional. Chanlat señaló que se debe restituir el encuentro de la subjetividad y lo afectivo dentro de la empresa familiar por medio de la aplicación de métodos cualitativos y recomendó “realizar entrevistas en profundidad, historia de vida, análisis de contenido y decodificaciones simbólicas" (Chanlat, 1994, p. 135). 
Dada la escasez de información sobre los procesos de toma de decisión al interior de una empresa familiar colombiana y cómo los significados compartidos inciden en dichos procesos, se planteó una investigación cualitativa que asumiera "que la realidad es múltiple, dinámica, global, y que se construye a través de procesos de interacción" (Vieytes, 2004, p. 669). Para ello, se estableció la interpretación de los discursos de un grupo directivo empresarial, al cual se tuvo acceso por medio de un proceso de consulta y negociación. El grupo familiar empresarial pertenece al sector de transporte terrestre en donde se pudo aplicar un conjunto de métodos cualitativos que permitieron extraer información relevante, y al tiempo construir un proceso de reflexión al interior de la empresa sobre el papel de los significados compartidos en la toma de decisiones.

Se siguió el método biográfico y se aplicó una guía de entrevista y observación que profundizó en la historia de vida familiar y empresarial de dicho grupo de personas, a través de un enfoque de corte constructivista. Se realizó un esquema analítico para comprender sus modos de vida y sus prácticas empresariales, relacionadas con la orientación en las decisiones alrededor del fundador de la empresa, y su hijo, el actual gerente. La técnica de recolección de información consistió en la aplicación de entrevistas en profundidad, las cuales desarrollaron ejercicios de función referencial, modal y de acto, lo que significa que se aplicó una entrevista abierta de tipo semiestructurada, para obtener información sobre los discursos y los modos de actuar de las personas y reconstruir los elementos que integran los significados compartidos a partir de la evidencia de un sistema de representaciones sociales desde el punto de vista de sus prácticas individuales y colectivas (Vieytes, 2004).

El modelo y los parámetros del instrumento de la entrevista de Spradley (1979) fueron centrales en el diseño de la guía. Al respecto y, con el interés de potencializar la validez interna del proyecto, se realizaron varias observaciones de corte etnográfico en eventos culturales de la empresa, tales como la celebración del día de la Virgen del Carmen, y 15 acompañamientos a días laborales de empleados y directivos en las oficinas principales de la empresa. Además de las visitas, se observaron las dinámicas de trabajo personales de los once informantes que fueron invitados a participar en el proyecto. Tres de los miembros de la junta directiva, que son los socios mayoritarios de la empresa, fueron entrevistados en dos ocasiones diferentes, por lo que se aplicaron en total catorce entrevistas en profundidad. ${ }^{1}$

1 Todas las entrevistas se realizaron personalmente. Vale aclarar que los nombres de los entrevistados se cambiaron para proteger su identidad. 
Frente a la cantidad de sujetos participantes se puede señalar que se logró una saturación de las categorías extraídas de la teoría de la ambigüedad e interpretación en la toma de decisiones empresariales (March, 1994) y que se realizó una transcripción de los apartados más relevantes. En la interpretación de las narrativas se extrajeron aquellos segmentos que se referían a los procesos de toma de decisiones en la organización familiar empresarial, los cuales se clasificaron en tablas de referencia por categorías de análisis y ejes de indagación. A partir de la saturación, se aplicó una técnica de análisis en tres momentos centrales evidenciados por Vieytes (2004, p. 674) tales como: "análisis preliminar, análisis intermedio y análisis final". El primero recolecta los datos hasta lograr la saturación; el segundo integra e interactúa con las fuentes de investigación y los métodos, y, por último, se identifican patrones comunes en los datos mediante comparaciones continuas y el reconocimiento de particularidades emergentes del estudio. En la figura 1 se ilustra el proceso de investigación iterativa, planteado por Yin (2009), el cual se siguió en el desarrollo del trabajo de investigación cualitativo.

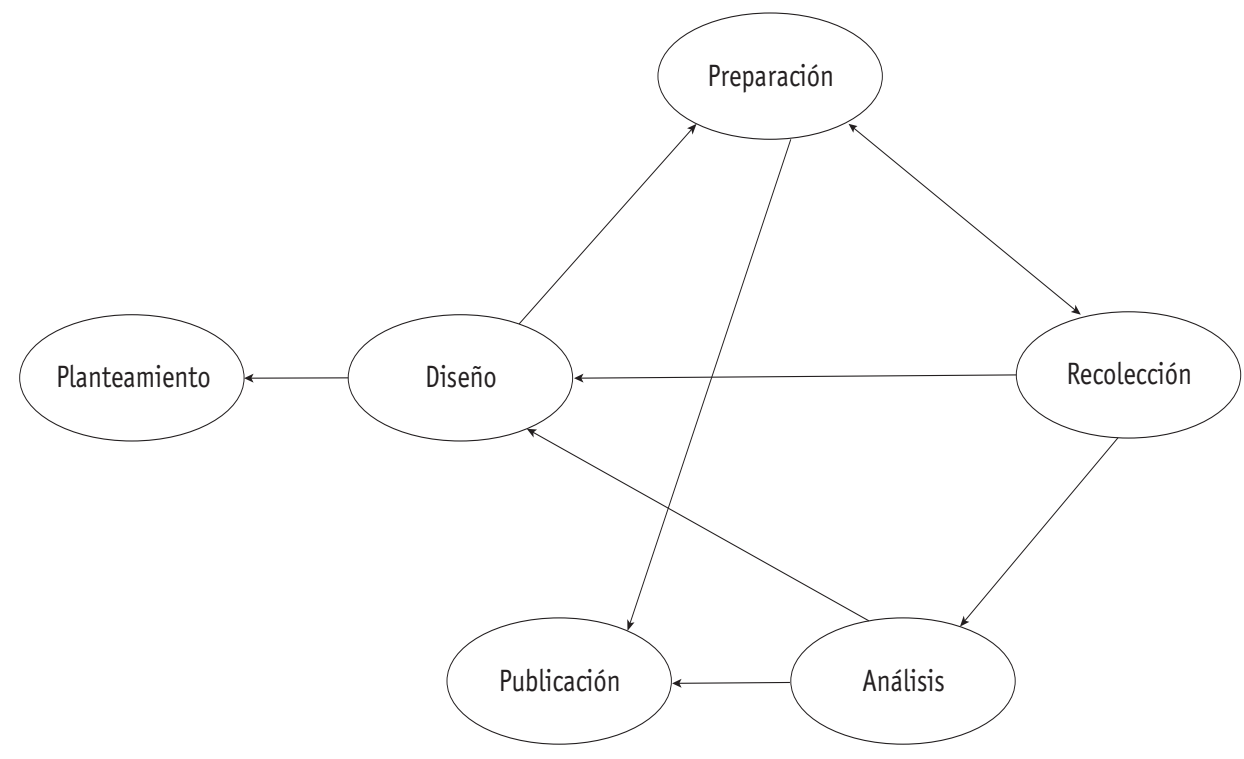

Figura 1. Proceso iterativo de investigación propuesto por Yin (2009).

Fuente: elaboración propia.

Acerca de los participantes entrevistados se señala que fueron, en orden de importancia familiar empresarial: el gerente general, el gerente comercial, los propietarios accionistas, la coordinadora de mercadeo comercial, quien es parte de la tercera generación familiar, 
la esposa del gerente, y la esposa del hijo mayor. También se entrevistaron empleados de la dirección con mayor antigüedad que no hacen parte del grupo familiar pero que tienen información clave sobre la historia empresarial y los significados compartidos: el revisor fiscal, la jefa de agencia, y una empleada operativa de taquilla. En cuanto a observaciones, se realizaron recorridos y acompañamientos laborales y familiares en oficinas de Antioquia y el Eje Cafetero, ${ }^{2}$ regiones en las que las decisiones gerenciales son más significativas.

La duración de cada entrevista fue de una hora y media hasta dos horas y los acompañamientos y visitas fueron en días laborales completos. Las investigaciones en Colombia que tienen en cuenta la organización familiar aplicando este tipo de metodología son particularmente escasas. Es importante aclarar que la organización familiar estudiada tiene sesenta años de trayectoria en el mercado de transporte terrestre y, por consiguiente, se debería considerar como modelo de trabajo de campo para futuras investigaciones. En este sentido, la metodología y los hallazgos presentados se pueden extrapolar a estudios de caso cualitativos que se centren sobre la investigación de organizaciones empresariales con características semejantes bajo condiciones teóricas similares (Yin, 2009).

\section{Resultados}

Se desagregaron los cuatro elementos que componen los significados compartidos (March, 1994) y se tuvieron en cuenta las dimensiones socioculturales para el proceso de categorización de los extractos de las entrevistas, como proceso de análisis de la información (Vieytes, 2004). De acuerdo con Geertz (1973), se aplicó el enfoque de la antropología simbólica que señala la emergencia de conceptos desde el trabajo de campo y luego contrasta el campo con la teoría existente, de modo que evidencian aspectos particulares y únicos de la realidad social que se estudió. Así, se clasificaron y describieron los actos sociales situacionales dentro de la empresa a partir de extractos de observación y entrevistas etnográficas realizadas. El cuadro 1 presenta el esquema de interpretación de los resultados. ${ }^{3}$

2 El Eje Cafetero es una región ubicada en el centro occidente de Colombia, que tiene una población de casi 4 millones de personas, en un territorio de 30 mil km2. Desde mediados del siglo XX la economía agrícola cafetera es la principal actividad económica, de los tres departamentos en que se divide la región: Caldas, Risaralda y Quindío.

3 En el enfoque cualitativo los datos recolectados en campo aportan al desarrollo teórico para contrastar la validez de la investigación realizada (Vieytes, 2004). Se pretende evitar tanto la sobre-interpretación como sesgar la lectura de los resultados con los conocimientos que se tienen (Frosh y Emerson, 2005). 


\section{Cuadro 1}

Esquema de interpretación de significados compartidos

\begin{tabular}{|c|c|c|c|}
\hline Símbolos & Mito & Historias & Rituales \\
\hline $\begin{array}{l}\text { a. Dominantes } \\
\text { b. Instrumentales } \\
\text { i. Emergentes } \\
\text { ii. Recesivos }\end{array}$ & $\begin{array}{l}\text { a. Fundador empresario } \\
\text { b. Patriarca familiar }\end{array}$ & a. El viaje del héroe & $\begin{array}{l}\text { a. Culturales } \\
\text { b. Empresariales }\end{array}$ \\
\hline
\end{tabular}

Fuente: elaboración propia.

\section{Las simbologías familiares que ingresan al mundo empresarial}

Según el orden propuesto por Eliade (1994), el símbolo se presenta como el elemento estructurador de las realidades presentes en los significados compartidos y es fundamental para la creación y la estructuración de las historias y los mitos. Estos se desagregaron en dos categorías propuestas por Turner (1999) como símbolos dominantes e instrumentales. Sin embargo, dentro de la categoría instrumental se propuso una segmentación nueva que se identificó como emergente y recesiva, puesto que en el proceso de análisis se reconoció que algunos de los elementos estaban en desuso -símbolos recesivos-, y otros elementos estaban en proceso de consolidación -símbolos emergentes-, lo que mostró que la categorización es más compleja en la realidad, que lo que la teoría de Turner había señalado. A continuación, se evidencian los órdenes propuestos que ayudan a comprender las dinámicas simbólicas en los procesos de toma de decisiones de la empresa familiar.

Categorías simbólicas dominantes de la empresa familiar en los procesos de toma de decisiones

\section{Extracto 1}

El 25 de julio es la celebración del día del conductor, alusivo a las fiestas de la Virgen del Carmen, patrona de nosotros los transportadores. En Medellín, los vehículos recibieron la bendición del padre -Sacerdote católico- que le echó agua bendita a cada carro... Los conductores son felices que el carrito reciba la bendición para que no les pase nada en la vía (coordinadora de mercadeo, comunicación personal, 29 de agosto de 2016).

\section{Extracto 2}

La foto nos acompaña en el auditorio, el cual lleva su nombre en su honor: todo mundo lo conoce, hasta el más nuevo; si pregunta quién es don Andrés, 
lo conocen, han escuchado hablar de él (Jefa administrativa, 14 de agosto de 2016, p. 8).

\section{Extracto 3}

Al gerente le gusta vestirse muy bien, igual que el fundador; a los dos les gustaba que los admiren (esposa del gerente, 11 de octubre de 2016, p. 21).

\section{Extracto 4}

La gente conoce la empresa por el nombre y los colores. Si usted pregunta, todos saben el color de nosotros (Jefa financiera, 29 de agosto de 2016, p. 2).

\section{Análisis Simbólico 1}

Los elementos simbólicos dominantes al interior de la empresa familiar fueron aquellos que se encuentran en relaciones culturales más amplias como la dimensión religiosa y estética. De esta manera, el gremio de los conductores tiene unas creencias y costumbres tradicionales arraigadas que están asociadas a prácticas religiosas colectivas e históricas tales como la creencia en la Virgen del Carmen (Barelli, 2012). La empresa no logra aislarse de estas dinámicas y termina por incorporar simbologías religiosas exteriores a la misma, lo cual define sus relaciones y prácticas sociales en el día a día (Turner, 1999). Otros elementos dominantes de tipo estético tales como la foto del fundador, presente en espacios emblemáticos de la empresa (gerencia, auditorio, oficina principal, etc.) y el vestido del gerente actual - que emula la vestimenta del padre fundador - evocan una imagen fuerte y un alto nivel emocional entre los integrantes de la empresa, que los relacionan con asuntos de autoridad, respecto y control (March, 1994). El último elemento que se consolida como dominante es la marca de la empresa, el cual tiende a constituirse como un puente en el mundo interior y exterior, a través del uso de los colores y la identidad corporativa, que se ha consolidado a lo largo de los 60 años de servicio a los usuarios de la empresa en el mercado local y nacional.

Categorías simbólicas instrumentales de la empresa familiar en los procesos de toma de decisiones

\section{Extracto 5}

En la mesita del rinconcito, con un mantel verde - color corporativo-, colocó uno de los busecitos miniatura de adorno y un ramito con flores, una veladora, un cristo y una velita de incienso (Gerente, 29 de agosto de 2016, p. 31). 


\section{Extracto 6}

En el 2012 participé en proyecto con la gerencia, para exponer la importancia de la tecnología en los carros, la innovación en pantallas individuales; no se trata solo de comodidad: el usuario actual depende de la tecnología y quiere estar conectado a redes sociales, entonces dotamos los carros nuevos con servicio de wifi (Accionista 2, 14 de agosto de 2016, p. 19).

\section{Extracto 7}

La empresa tiene un escudo, pero no lo recuerdo... nos explicaron una vez, sé que tiene un significado, creo que las manos son el cooperativismo de los trasportadores, pero los otros elementos no los recuerdo muy bien (Accionista 1, 14 de agosto de 2016, p. 7).

\section{Análisis Simbólico 2}

Un conjunto de símbolos religiosos, empresariales y ritualísticos sirven para reforzar la presencia del padre a través de la construcción de un altar familiar. Los símbolos instrumentales se articulan para reforzar ciertos propósitos que, en este caso, son de tipo organizacional (Dyer, 1988). Se encontraron algunos símbolos instrumentales emergentes tales como discursos de tecnología y la implementación de elementos de competitividad en el mercado para satisfacer la demanda de los clientes del transporte tales como las normas ISO. Así, tecnología y sellos de calidad se identifican como elementos simbólicos emergentes en la construcción de significados para la comunicación entre los empleados y los miembros de las nuevas generaciones de la empresa. Por otro lado, se encontraron símbolos instrumentales recesivos tales como el escudo, el cual ha dejado de ser significativo en sus estrategias de información o de identificación organizacional, pues ninguna de las personas entrevistadas logró una interpretación compartida sobre su significado; prevaleció su desconocimiento.

\section{El origen mítico del empresario fundador y patriarca}

Para el caso de la empresa familiar estudiada, el mito se compone por un hombre de dos caras: fundador y patriarca. Ambos roles se fortalecen mutuamente. Por un lado, al ser el padre de familia se le considera el sustento emocional y simbólico que los une en torno a una causa y una misión empresarial. Y, por otro lado, como fundador, se le profesan rituales y se le atribuyen características que van del orden profano al sagrado 
y que juegan un papel central en las situaciones en que se toman decisiones para el futuro de la empresa.

Además, el papel del mito filtra aspectos de la historia que se mantienen vigentes pero que se van depurando en la memoria de las personas para dejar un personaje más claro, coherente y centrado de lo que en realidad fue su fundador en vida. Así se evidenció que el elemento constitutivo central del fundador y patriarca en su historia empresarial se asemeja al viaje del héroe (Campbell, 2001). ${ }^{4}$ Durante la reconstrucción de la historia de vida de don Andrés como creador de la empresa de transporte terrestre, los entrevistados coincidieron en señalar que su trasegar es desde la seguridad hacia un conjunto de retos, que terminan en la consolidación de la empresa familiar y el mantenimiento de un orden tradicional. Esta narrativa se evidenció en la toma de decisiones colectivas por parte de los miembros de la junta directiva de la compañía.

\section{Categorías míticas del fundador empresario en la toma de decisiones}

\section{Extracto 8}

A la hora de tomar las decisiones, él era más inmediato, menos analítico; más impulsivo y pasional. Antes, nuestros padres y abuelos trabajan así, al cálculo, de forma empírica (Gerente, 15 de agosto de 2016, p. 28).

\section{Extracto 9}

Don Andrés fue un visionario: tenía una gran capacidad de análisis macro, aunque le faltaba la parte administrativa de lo micro (Esposa de gerente, 10 de octubre de 2016, p. 18).

\section{Extracto 10}

Junto con mi hermano decidimos comprar dos buses, pero yo dije: compremos el tercero para que sea el del abuelo, así ya no esté... Estaba recién fallecido y estábamos comprando los buses, y pensé: "él hubiera dicho ¡pidan, pidan que yo lo compro!". Así que cogí una cábala y sumé la fecha de su nacimiento y me arrojó el número de su bus" (Gerente, 29 de agosto de 2016, p. 31).

4 El héroe de las mil caras es un libro publicado en 1949 por el mitógrafo estadounidense Joseph Campbell, que trata del viaje del héroe, o monomito, es decir, un patrón narrativo transversal a las historias y leyendas populares en muchas culturas ancestrales a nivel mundial, en donde Campbell toma como patrón el mito del héroe griego Hércules y los retos que enfrentó a lo largo de su historia. 


\section{Extracto 11}

Muchas veces repelente a los cambios, a la modernización y a las exigencias del gremio (Gerente, 29 de agosto de 2016, p. 31).

\section{Análisis Simbólico 3}

El fundador tiene atributos de visionario, empírico, impulsivo y pasional. Todas estas características juegan en la consolidación de una imagen heroica que le da a su legado una dinámica actual y certera, en los roles de los hijos que lo sucedieron. De esta manera, la admiración por el padre, está mezclada con el reconocimiento hacia el fundador, líder empresario y familiar. El fundador se convierte en un elemento clave de la estructuración de las decisiones que se toman en la empresa (Dyer, 1988; March, 1994). Así, se piensa como si fuera el fundador quien estuviera tomando la decisión y se refuerza con símbolos de su presencia, tales como el número de su cábala. Algunos de los aspectos contradictorios en los que el fundador es reticente, refuerzan el rol del viaje del héroe a lo largo de su devenir histórico y social (Campbell, 2001).

\section{Categorías míticas del patriarca familiar en la toma de decisiones}

\section{Extracto 12}

Mi padre fue querendón -sin ser el más meloso-, con un gran corazón, dadivoso y con buen sentido del humor, buen negociante y comerciante, abierto a las personas, ayudaba a la gente, daba buenos consejos a amigos, familia, es el papá de mucha gente. Alguna palabrita de don Andrés era sagrada, como la bendición para la gente (Gerente, 15 de agosto de 2016).

\section{Extracto 13}

Era fraternal, pero en esa paternidad infundía respeto, nunca se confundió su amabilidad y humildad pues era una mezcla de amabilidad y respeto (Miembro de junta directiva, 29 de agosto de 2016, p. 16).

\section{Extracto 14}

Cuando falleció, los que estaban alejados se reconciliaron. Su muerte nos unió como familia pues nos dejó tanto amor, enseñanzas y la responsabilidad de continuar la lucha por lo construido (Coordinadora de mercadeo, 27 de agosto de 2016). 


\section{Análisis Simbólico 4}

Se puede evidenciar como la imagen del patriarca familiar trasciende las fronteras de la familia y se inserta en el mundo empresarial. Su papel emocional bajo categorías tales como generoso, querendón y amoroso, cruzan los espacios institucionales y se inserta en ellos para dar cuenta del posicionamiento entre los empleados y clientes como "el papá de mucha gente" y su palabra en el orden de lo sagrado (Dyer, 1988; Eliade, 1994).

El tratamiento de "don" le atribuye respeto, protocolo, deferencia, distinción y reputación en la familia y en círculos más amplios de población. Se fusiona la imagen mítica de dos arquetipos centrales. La mezcla de liderazgo con respeto se aúna a la fraternidad de un padre amoroso y humilde. En este sentido, la imagen del paterfamilias se refuerza y fortalece con la de empresario fundador. La muerte del patriarca es integradora y define un camino para el grupo que debe continuar. Sus valores se resaltan y el propósito empresarial y familiar se establece (Eliade, 1994).

\section{El viaje del héroe como historia cultural y empresarial}

Según Campbell (2001), el viaje del héroe tiene doce momentos, que se agrupan en la tríada: separación, iniciación y retorno. Se utilizó dicha agrupación, para realizar la construcción de la historia cultural y empresarial de la empresa de transporte terrestre. Sin embargo, se evidenció que su estructura de monomito o patrón narrativo mítico tradicional, contiene elementos centrales del viaje del héroe, lo que quiere decir que se pueden encontrar en formación ciertos elementos y procesos de dicha teoría, aunque no todos. En este sentido, se aporta información sobre la constitución del camino del héroe en contextos culturales ajenos a los que Campbell investigó, y que, en este caso, se describe como la misión empresarial con trascendencia a la familia del patriarca.

Al seguir la línea de los significados compartidos de March (1994) y los puntos de inflexión en la historia de vida de Vieytes (2004), se encuentra que el contexto histórico de formación empresarial se cruza con la vida del patriarca-fundador y las categorías de la triada del héroe de Campbell (2001). De esta manera, los significados compartidos sobre la historia empresarial se convirtieron en el elemento de mayor coherencia entre los entrevistados, lo que hizo de estos elementos teóricos los mejor articulados en cada entrevista, pues se repitieron de manera clara y precisa. 
Categorías históricas de la empresa familiar en la toma de decisiones

La historia emergente no correspondió a la triada de Campbell, pero ello no significa que no se puedan realizar agrupaciones sobre las historias compartidas por los miembros de la familia - empresa. En este caso, se procedió a crear un conjunto alternativo que siguió la historia del héroe y la consolidación de la empresa, y que se cumple en cuatro tiempos narrativos que se describen a continuación:

\title{
CREACIÓN DE LA EMPRESA Y SEPARACIÓN DEL MUNDO ORDINARIO
}

\author{
Extracto 15 \\ La organización de transporte terrestre fue fundada en 1957. Su fundador, don An- \\ drés, fue empleado de la empresa en la que empezó siendo un "todero" (Gerente, \\ 15 de agosto de 2016, p. 24).
}

\section{Extracto 16}

Le dijeron: don Andrés, no tenemos como pagarle y gracias a todo lo que ha hecho; le queremos ofrecer unas acciones (Miembro junta directiva, 29 de agosto de 2016, p. 12).

\section{Análisis Simbólico 5}

Se trata del mundo ordinario del héroe antes empezar su viaje. En esta posición el fundador aún no conoce su potencial ni ha adquirido su rol de patriarca. De empleado a propietario, el héroe se encuentra en la llamada a la aventura, en la que se le presenta un problema y la aventura-desafío comienza.

\section{UNIFICACIÓN DEL PODER E INICIACIÓN DEL DESAFÍO}

\section{Extracto 17 \\ Quedaron tres socios y cuando uno de ellos murió hubo conflictos entre don Andrés y don Esteban. Los desacuerdos dañaron la relación laboral y decidieron negociar: así convencieron a don Andrés de quedarse como único propietario pues tenía más gente para colaborarle (Socia 1, 29 de agosto de 2016, p. 5).}




\section{Extracto 18}

Una de las decisiones más significativas tomadas por don Andrés fue adquirir más rutas y mejorar equipos, modernizar y abrir agencias nuevas en las rutas (Socia 1, 15 de agosto de 2016, p. 9).

\section{Extracto 19}

Don Andrés reunió a sus hijos y les informó que quería involucrarlos y que los necesitaba para sacar la empresa adelante. Ellos regresaron con su padre y trabajaron en la empresa (Accionista 2, 1 de noviembre de 2016).

\section{Análisis Simbólico 6}

El héroe tiene cierta reticencia y el miedo al cambio lo limita. Sin embargo, según Campbell (2001), la ayuda divina y el apoyo del grupo, insta al héroe a aceptar la misión y asumir el liderazgo para consolidarse como fundador y único propietario de la empresa familiar. ${ }^{5}$ El fundador cambia la realidad y transforma el mundo ordinario en una nueva realidad empresarial. La compañía se expande y nunca más vuelve a ser la misma. Las pruebas familiares y empresariales lo llevan a buscar en sus hijos aliados en quienes confiar. También unificó el poder familiar al controlar a los hijos a través de la empresa: gerente y patriarca.

\section{TRANSICIÓN Y HERENCIA MASCULINA: ÉXITOS, PRUEBA FINAL Y PREMIOS}

\section{Extracto 20}

En la empresa cubrí varias áreas: fui asistente, recaudé dinero en taquilla, realicé consignaciones, hice cuentas y liquidaciones de afiliados y propietarios (Gerente, 15 de agosto de 2016, p. 24).

\section{Extracto 21}

Hubo una crisis por malos manejos internos y problemas personales de don Andrés. Un gerente provisional empeoró todo. Así que don Andrés decidió entregar su legado a su hijo menor ${ }^{6}$ para ocupar la gerencia de la empresa (Socia 1, 29 de agosto de 2016, p. 8).

5 La empresa pasó por diferentes personas jurídicas: primero fue sociedad limitada, luego en comandita por acciones y en la actualidad es sociedad anónima.

6 Los otros dos hijos hombres se encontraban imposibilitados mientras que la hija no fue considerada por el padre. 


\section{Extracto 22}

Con posterioridad se hicieron inversiones a través de leasings que permitieron comprar buses de dos pisos para modernizar la empresa (Esposa del gerente, 11 de octubre de 2016).

\section{Extracto 23}

Asumir la gerencia significó el cambio de personal y la aplicación de normas como la IS0 9001 para poder progresar (junta directiva, 14 de agosto de 2016, p. 7).

\section{Análisis Simbólico 7}

El hijo que detenta el poder de la empresa inició su trayecto desde la base a semejanza del padre fundador. Los valores de este, lo transformaron en un adalid que continuará la misión. De este modo, el hijo se constituye como el líder heredero, sobre el temple del héroe que generó dificultades y llevó a la organización a enfrentar problemas financieros. Es por esto que el heredero logra continuar la misión del padre fundador, quien es reemplazado.

Al transmitir el poder, el legado continúa y se cumple la misión del héroe. La recompensa final es el reconocimiento del rol del hijo que recibe la misión del padre y se articula en su voluntad para manejar la empresa y la familia. Será como una carrera de relevos en donde se entrega el testigo a la siguiente generación. La dirección empírica dio paso a una dirección administrativa y profesional con planeación y dirección. Aun así, la figura del padre sigue apareciendo con réditos y soluciones para cumplir la misión empresarial.

\section{FUTURO DE LA EMPRESA FAMILIAR Y EL REGRESO AL MUNDO ORDINARIO}

\section{Extracto 24}

La sucesión está diseñada para dentro de ocho años. Estaré en la empresa, aprendiendo y conociendo diferentes áreas hasta llegar a gerente acompañada por él como guía (Coordinadora de mercadeo, 29 de agosto de 2016).

\section{Extracto 25}

Está muy bien posicionada, más capacitada desde el punto de vista profesional y la empresa constituida para continuar su funcionamiento en el futuro (Gerente, 15 de agosto de 2016, p. 24). 


\title{
Análisis Simbólico 8
}

El regreso a los orígenes se interpreta en la adopción de un modelo gerencial claro en el que, además la mujer, como descendiente directa del hijo menor heredero, reemplaza a su padre y continua el rol como adalid de la imagen del fundador-patriarca. La empresa adquiere una misión estable en el tiempo y el orden de las cosas se reestablece por medio de nuevos elementos para su funcionamiento.

Hasta este punto, se identifica que la historia y mito del fundador y patriarca de la empresa se consolidan en dos elementos articulados que inciden en los procesos de toma de decisiones gerenciales al interior de la empresa familiar. Los extractos señalados además de haber sido identificados en todas las entrevistas, muestran un alto grado de coherencia interna, que adjudica el papel más importante al rol del padre fundador y su legado que se transmite a lo largo de las generaciones venideras, no sin aceptar que algunos cambios estructurales comienzan a suceder como la entrada de la mujer dentro de roles gerenciales y administrativos, lo cual fue evitado por el fundador durante el ejercicio de su mandato con su propia hija.

\section{Rituales en las dinámicas empresariales y familiares}

El último de los elementos de los significados compartidos señalado por March (1994) es uno en el que articula de mejor manera, la trayectoria de los elementos anteriores y que, además, refleja con claridad los procesos de toma de decisión. Se segmentaron los rituales identificados en dos tipologías: cultural y empresarial. Según Goffman (1956), existen rituales conversacionales entre dos o más personas, que participan en escenarios micro-sociales diarios, señalando la importancia de una realidad compartida entre quienes hablan una misma lengua. Estos rituales fueron encontrados en los resultados de las entrevistas. Ambas dimensiones ritualísticas conjugan símbolos, mitos e historias que fortalecen el proceso de toma de decisiones orientado hacia el desarrollo de la empresa y el cumplimiento del propósito empresarial y de la visión de empresa del fundador-patriarca.

Rituales de tipología cultural en la empresa familiar en la toma de decisiones

\author{
Extracto 26 \\ La celebración de la Virgen del Carmen es nuestra fiesta, ella es nuestra patrona. \\ (Coordinadora de mercadeo, 29 de agosto de 2016)
}




\title{
Extracto 27
}

Todas las empresas se unen y ponen aportes económicos; se celebran misas, se hacen fiestas y hay rituales en cada una (Esposa del gerente, 10 de octubre de 2016).

\section{Análisis Simbólico 9}

El proceso de construcción social identitaria entre los transportadores como sector económico en el desarrollo del país marca un hito en las dinámicas laborales de la empresa y atraviesa todas las instancias institucionales, desde la dirección hasta la base operativa. El colectivismo laboral y social no solo es un puente entre las empresas competidoras en el sector, sino que además indica la forma en que se construyen vínculos de solidaridad y amistad que ayudan a que los transportadores estén cohesionados por medio de un instrumento ritualístico que les permite desarrollar procesos identitarios formativos y seculares/sagrados propios.

Rituales de tipología empresarial en la empresa familiar en la toma de decisiones

\author{
Extracto 28 \\ Mi papá hubiera dicho tal cosa, ahí está pintado él, y recordamos cuando él hablaba \\ y lo que decía, entonces de pronto utilizamos palabras que él estaba acostumbrado \\ a usar y decimos: "ahí está papá presente tomando decisiones"; hay algo divino, \\ algo diferente (Junta directiva, 29 de agosto de 2016, p. 20).
}

\section{Extracto 29}

Cuando hacemos las asambleas hay un ritual iniciar: himno nacional, se leen unas oraciones por los enfermos y en la mesita del rincón está el altar con los busecitos miniatura y las flores, la veladora, el cristo y el incienso (Gerente, 29 de agosto de 2016, p. 31).

\section{Análisis Simbólico 10}

Las prácticas internas aparecen en situaciones específicas en las que se apela a la presencia del padre en forma divina y su imagen está vigente en los procesos en los que se toman las decisiones de la empresa. Se recuerda su nombre, se le pide guía y apoyo, y se comprende su historia, no solo en la dimensión familiar sino en la empresarial. Las 
reuniones de gerencia, junta directiva y las prácticas discursivas de los miembros de la familia, señalan los elementos articulados y compartidos por el grupo directivo. Estos elementos ritualísticos señalan la conexión para que las decisiones en la empresa tengan una coherencia interna que solo los rituales logran articular cuando se trata de evitan malentendidos y el surgimiento de diferencias que no son aceptadas por el grupo empresarial.

\section{Análisis y discusión}

La comprensión de cómo los significados compartidos inciden en la toma de decisiones en la empresa familiar estudiada se logró identificar a partir del desarrollo de los elementos señalados por March (1994). Estos conceptos fueron el sustento teórico y propositivo para reconocer su importancia en la construcción de las estrategias gerenciales. Es de señalar que el trabajo de observación y entrevistas realizado, se ejecutó bajo parámetros metodológicos cualitativos (Spradley, 1979; Vieytes, 2004). Además, la formulación de proposiciones estuvo centrada directamente en el reconocimiento de categorías de análisis provenientes de la literatura, así como en la emergencia de conceptos en el trabajo de campo, por el cual tanto el área de investigación como las disciplinas, avanzan en el conocimiento de los problemas mediante aportes y relevancia temática (Geertz, 1973; Harris, 1980).

A continuación, se da cuenta de cómo cada uno de los elementos que se constituyeron en significados compartidos al interior de la empresa, incidieron en la toma de decisiones y se consolidaron como herramientas de investigación relevantes para el área y para futuros desarrollos metodológicos. En primer lugar, se encuentran los símbolos que fueron segmentados en dos conjuntos diferentes: dominantes e instrumentales. Los dominantes se evidenciaron en discursos y prácticas compartidas por los integrantes de la empresa y del sector transportador colombiano. En este sentido, el símbolo dominante por excelencia es religioso, y aparece bajo la forma de la organización de la empresa, a partir de la celebración de una fiesta y ceremonias colectivas que integran a varios órdenes jerárquicos. Otros símbolos dominantes se evidenciaron en la imagen fotográfica del fundador y la réplica de su vestimenta por parte del actual gerente. En este caso, el orden simbólico apela a un sentido estético que caracterizó el rol del fundador y su papel en la consolidación de la empresa, pero también de la familia.

Por otro lado, los símbolos instrumentales se presentaron como reforzadores y acompañantes del conjunto simbólico empresarial. Así, con la imagen de la Virgen, se mezclan 
crucifijos, altares y velas, mientras que, en los micro-rituales corporativos, las imágenes de Don Andrés surgen en citas que recuerdan eventos y palabras dichas en el pasado, pero que afectan los modos de discutir y resolver conflictos y problemas en el presente. Por consiguiente, la influencia religiosa y estética en los espacios de decisión de la empresa se evidencia como un proceso colectivo de significación en donde las decisiones corporativas toman lugar.

En segundo lugar, los símbolos contribuyen a la creación del mito empresarial: el del héroe fundador-patriarca. En este caso, el mito tiene un rol central en la configuración emotiva de los integrantes del grupo familiar que se involucran en las decisiones de la empresa. Su imagen, su presencia y su estructura mental continúan vigentes entre directivos, empleados y familiares, lo que hace que el proceso de toma de decisiones sea una dinámica organizacional ritualizada. La importancia del padre-fundador como mito centralizador se evidenció de este modo: “En cuanto a muchas decisiones, tenemos en cuenta al fundador, particularmente su visión, que dejó para que nosotros cumpliéramos con la misión, volviendo el tiempo atrás, de cómo él hubiera hecho las cosas para nosotros poderlas ejecutar" (Junta directiva, 18 de marzo de 2017).

En relación con lo anterior, se evidenció que la actual investigación enriquece con un aporte significativo al área de los estudios de las empresas familiares, al confrontar los modelos funcionales y estructurales, y señalar que la visión de empresa como prolongación de la familia para el uso de un recurso, es la más adecuada para abordar este tipo de organizaciones. Aunque muchos autores abordan esta realidad de manera indirecta, no la definen ni la caracterizan, por lo cual, este estudio propone una nueva clasificación y definición de la empresa familiar según términos operativos, estructurales y emocionales, integrados en un conjunto de dinámicas socioculturales.

Por otro lado, se agregó a la clasificación de símbolos de Turner (1999) una nueva subcategoría de estudio de los elementos simbólicos que circulan al interior de la empresa, que se encuentran dentro de los símbolos instrumentales: denominados emergentes y recesivos. Esto se debe tener en cuenta en futuras investigaciones, dado que muchos elementos están circulando con diferentes dinámicas de poder desde y hacia las organizaciones empresariales, o emergen y se reciclan en las dinámicas de creación e innovación, por lo cual es importante reconocer en qué medida los símbolos instrumentales son parte de las dinámicas de los significados compartidos por los grupos que conforman los procesos de toma de decisión. 
En este sentido, la historia contada por los participantes de la investigación se encuentra en constante transformación, en donde se evidencia un proceso inicial de depuración en la que se han filtrado asuntos personales, empresariales y económicos, que generan diferencias, pero que, a partir del cumplimiento del viaje del héroe, garantizan que la empresa continúe operando de acuerdo con las necesidades del mercado y que se cumplan los requerimientos básicos de funcionamiento. Ambos elementos, mito e historia, no deben separarse en su comprensión pues "la sustancia del mito, no se encuentra ni en el estilo, ni en el modo de la narración, ni en la sintaxis, sino en la historia relatada" (Lévi-Strauss, 1987, p. 233).

En el caso de esta empresa familiar, con la interpretación simbólica, se evidenció que la toma de decisiones no es del todo racional, sino que es incidida por el mito y la historia del fundador, e involucra elementos simbólicos y emocionales compartidos por la familia empresarial y la junta directiva que toma las decisiones corporativas. El viaje del héroe está en un proceso central integrador, que incluso abarca la vida y la obra del hijo menor dentro de la empresa en el cumplimiento de la misión señalada por el padre (Campbell, 2001). Por consiguiente, la historia y el mito no son relatos continuos en el tiempo, sino que se ven afectados por las narrativas emocionales y simbólicas de quienes las cuentan. Se crea de este modo, un eje narrativo sincrónico, que determina un orden ideal desde los imaginarios culturales construidos por el grupo de referencia. Es por esta razón que el mito emerge y se alimenta del presente con nuevas realidades que lo prolongan a través de experiencias exitosas (Levi-Strauss, 1987).

En esta dirección, la historia del héroe fundador-patriarca refuerza permanentemente la identidad empresarial y mantiene el conjunto de valores vigentes en el presente a través de su incidencia en los procesos de decisión de generaciones posteriores. Es por ello, que se considera que el mito y la historia no pueden separarse pues ambos contribuyen a la comprensión de los modos en que la realidad opera en una situación particular (Dumézil, 2016).

Finalmente, los rituales surgen como el cuarto mecanismo en los significados compartidos y aparecen como un conjunto de procedimientos articulados que se recrean en el presente y de los cuales la empresa no puede aislarse: se trata de horizontes de desarrollo y proyección empresarial. Debe señalarse que las tradiciones culturales no son ajenas al grupo empresarial y que en ellas se agrupan lógicas de trabajo y de servicio que coexisten entre la sociedad y el segmento empresarial del transporte, en las que, además, el respeto por los padres, ayudar a los necesitados y los enfermos, y bendecir 
el trabajo para el bienestar de los grupos sociales que dependen de él, son realidades transversales dentro y fuera de la empresa para quienes toman las decisiones. Las prácticas y rituales religiosos que refuerzan la sociedad patriarcal como la adoración de la Virgen, la veneración del padre y la bendición de los vehículos, pudieron ser observadas en distintos momentos durante la investigación, lo que permitió realizar una validación de la operación de los otros elementos dentro de la realidad empresarial. De este modo, se pudo comprender cómo los procesos de toma de decisiones fueron incididos por el conjunto de significados compartidos por el nivel directivo en el caso de la empresa familiar de transporte estudiada.

Se puede incidir que, si bien las empresas familiares toman decisiones racionales, hay otra realidad al interior de ellas, que opera bajo dinámicas emocionales y simbólicas, que afecta los procesos de toma de decisión al interior de las mismas. Al evidenciar esta realidad dentro de una empresa familiar de transporte terrestre se debe señalar que, si bien el mercado colombiano está compuesto por una mayoría de empresas familiares, la metodología propuesta y el análisis realizado, permiten estructurar un proceso de investigación que extrapola los resultados encontrados a otras dimensiones organizacionales con características similares, tanto en Colombia como en Latinoamérica (Yin, 2009).

Dado que se evidencia la ausencia de estudios que realizan este tipo de aproximaciones a la realidad empresarial familiar, futuros proyectos y propuestas de investigación tienen en este estudio un aporte único para la investigación de dimensiones socioculturales que operan al interior de las empresas familiares. Esto evidencia la necesidad de implementar más estudios enfocados en las dinámicas de los elementos de la teoría de los significados compartidos de March. En el caso específico estudiado, el mito y la historia se consolidaron como dos de los elementos de mayor relevancia en la constitución de los discursos y las acciones empresariales. En futuros desarrollos, se podría constatar la relevancia de otros aspectos tales como los símbolos y los rituales.

\section{Conclusiones}

El presente estudio cualitativo deber ser evaluado como una puerta de entrada y una invitación a profundizar en el estudio de la empresa familiar desde nuevos enfoques metodológicos tales como el cualitativo con la aplicación de abordajes interpretativos que tengan en cuenta la perspectiva organizacional simbólica y antropológica. 
En relación con lo anterior, estudios en el área deben considerar dimensiones socioculturales que tengan en cuenta la transversalidad interdisciplinaria, o sea, que integren una visión de empresa más amplia que aborde otras dinámicas como las simbólicas. De esta forma, el estudio contribuye a aportar nuevas variables y consideraciones que de otra manera no podrían ser notadas y que juegan un rol central, como se evidenció en la prolongación de la empresa en el tiempo y el cumplimiento de las metas y propósitos familiares.

Dado que el estudio se realizó en una empresa en particular, se encontró que la misma cumple los patrones de una cultura paternalista descrita por Dyer (1988). Según el autor, existen cuatro tipos de patrones culturales en empresas familiares (cultural paternalista, cultural permisivo, cultural participativo y cultural profesional), por lo que se considera que el presente estudio aporta en el conocimiento de este patrón cultural en el mercado latinoamericano. Además, se recomienda aplicar un estudio posterior que considere la comparación del proceso de toma de decisión en empresas familiares colombianas que se encuentren en diferentes patrones culturales.

En cuanto a las limitaciones de la investigación se señala que se trató de un estudio interpretativo de la realidad simbólica sobre los contenidos provenientes de observaciones y entrevistas a una sola empresa y un único grupo familiar, por lo que los resultados no deben ni pueden ser extrapolados a otros segmentos y categorías de mercados. Esto no significa que no se pueda utilizar el esquema propuesto de la tabla 1 a futuras investigaciones.

Por otro lado, debe señalarse que, aunque la empresa familiar facilitó el acceso a observaciones y entrevistas con los miembros de la firma por parte del investigador de modo independiente, no aceptó su presencia en ninguna de las asambleas de accionistas, pues se consideró que no era el espacio indicado para desarrollar los objetivos de la investigación. Se recomienda en este sentido que en el futuro otras investigaciones lleven a cabo ejercicios comparativos empresariales en diferentes segmentos, al igual que se plantee el estudio longitudinal de un grupo de empresas para evaluar sus dinámicas socioculturales y simbólicas, con el propósito de corroborar algunos de los patrones evidenciados en el presente estudio.

Por último, se destaca la posibilidad de acceder a los discursos del grupo familiar empresarial sobre dinámicas cotidianas, lo cual prepara el terreno para que otros investigadores puedan avanzar en nuevos trabajos centrados en las realidades simbólicas 
de las empresas familiares colombianas, sobre todo en la vertiente de los significados compartidos. Con este propósito se hace énfasis en señalar que el mito y la historia fusionan como constructos de alta incidencia en los procesos de toma de decisión y se evidencian en dinámicas ritualísticas empresariales. El uso de enfoques etnográficos de tipo interactivista-simbólico, con la aplicación de metodologías biográficas, permitió adentrarse en el seno de una organización compleja como lo es la empresa familiar en sus generaciones segunda y tercera.

\section{Referencias}

Arenas, H. y Rico, D. (2014). La empresa familiar, el protocolo y la sucesión familiar. Estudios Gerenciales, 30(132), 252-258.

Argyris, C. \& Schön, D. A. (1978). Organizational learning: A theory of action perspective. Reading, MA: Addison-Wesley Publishing Company.

Barelli, A. I. (2012). La Virgen de Caacupé como símbolo de paraguayidad en Bariloche, Argentina, 1970-2012. Revista de Estudios Latinoamericanos, 58, 205-236.

Bastar, S. A. (2013). Familia y empresa familiar: un caso de éxito en la intersección de estas instituciones. México: Universidad Autónoma de México.

Benavides, C. A., Guzmán, V. F. y Quintana, C. (2011). Evolución de la literatura sobre empresa familiar como disciplina científica. Cuadernos de Economía y Dirección de la Empresa, 14(2), 78-90.

Björnberg, A. \& Nicholson, N. (2012). Emotional ownership: the next generation's relationship with the family firm. Family Business Review, 25(4), 374-390.

Campbell, J. (2001). El héroe de las mil caras: psicoanálisis del mito. México: Fondo de Cultura Económica.

Carrasco, H. A. y Rubio, B. A. (2007). Análisis de las prácticas de recursos humanos en las pymes familiares de éxito. Revista de Empresa, 22, 20-34.

Casillas, J. C., Díaz, C. y Vásquez, A. (2005). La gestión de la empresa familiar: conceptos, casos y soluciones. Madrid: Thomson.

Chandler, A. (1962). Strategy and Structure. Boston, MA: MIT Press.

Chanlat, J.-F. (2002). Ciencias sociales y administración. En defensa de una antropología general. Medellín: Fondo Editorial Universidad EAFIT.

Chirico, F., Nordqvist, M., Colombo, G. \& Mollona, E. (2012). Simulating dynamic capabilities and value creation in family firms: Is paternalism an 'asset' or a 'liability'? Family Business Review, 25(3), 318-338.

Chua, J. H., Chrisman, J. J. \& Steier, L. P. (2003). Extending the theoretical horizons of family business research. Entrepreneurship Theory and Practice, 27, 331-338. 
Cisneros, L., Ramírez, G. y Hernández, A. (2011). Control en la empresa familiar. AD-Minister, 18, 49-76.

Cruz, C. M., Ramírez, C. M., Lozano, 0., et ál. (comps.) (2013). Organizaciones y familia. Experiencias en México y España. México: Hess, Universidad Autónoma de Chiapas, Universidad Autónoma Metropolitana y Nodo Empresa Familiar y Mipyme de la Red Mexicana de Investigación en Estudios Organizacionales.

De la Garza, M. I., Medina, J. M., Cheín, N. F. et ál. (2011). Los valores familiares y la empresa familiar en el nordeste de México. Cuadernos de Administración, 24(42), 315-333.

De la Rosa Albuquerque, A., Lozano Carrillo, 0., \& Ramírez Segura, J. C. (2009). Organización, empresa y familia: de la empresa familiar a la organización familiar. Gestión y Estrategia, 36, 17-36.

Dumézil, G. (2016). Mito y epopeya. La ideología de las tres funciones en las epopeyas de los pueblos indoeuropeos. México: Fondo de Cultura Económica.

Dyer Jr., W.G. (1988). Culture and continuity in family firms. Family Business Review, 1(1), 37-50.

Eliade, M. (1994). Mito y realidad. (L. Gil, Trad.). Barcelona: Labor.

Etkin, J. R. (2006). Gestión de la complejidad en las organizaciones: la estrategia frente a lo imprevisto y lo impensado. Buenos Aire: Ediciones Granica S.A.

Fajardo, L. H. (1969). La moralidad protestante de los antioqueños: estructura social y personalidad. Cali: Universidad del Valle.

Frosh, S. \& Emerson, P. D. (2005). Interpretation and over-interpretation: Disputing the meaning of texts. Qualitative Research, 5(3), 307-324.

García, C. M. (2005). Una aproximación al concepto de cultura organizacional. Universitas Psychologica, 5(1), 163-174.

Garmendia, J. (1988). La cultura de la empresa: una aproximación teórica y práctica. Revista Española de Investigaciones Sociológicas, 41(88), 7-23.

Geertz, C. (1973). La interpretación de las culturas. Barcelona: Gedisa.

Gentilin, M. y Gonzales-Miranda, D. (2017). Reflexiones en torno a la intervención socioeconómica del ISEOR. El caso de una organización familiar mexicana. Teuken Bidikay, 8(10), en prensa.

Ginebra, J. (2001). Las empresas familiares: su dirección y su continuidad. México: Panorama.

Goffman, E. (1956). The presentation of selfin everyday life. Edinburgh: University of Edinburgh Social Science Research Centre.

González, R., Hernández, G. y Rodríguez, L. (eds.) Organizaciones y familia: experiencias en México y España. México: Grupo Editorial Hess.

Harris, M. (1990). Antropología cultural. Madrid: Alianza editorial. 
Heirs, B. \& Pehrson, G. (1972). The mind of the organization: On the relevance of the decisionthinking process of the human to the decision-thinking process of organization. New York: Harper \& Row.

Hollander, B. S., \& Elman, N. S. (1988). Family-owned businesses: An emerging field of inquiry. Family Business Review, 1(2), 145-164.

Kaslow, F. (1993). The lore and lure of family business. American Journal of Family Therapy, 21(1), 3-16.

Koropp, C., Kellermann, F. W., Grichnik, D. \& Stanley, L. (2014). Financial decision making in family firms: an adaptation of the theory of planned behavior. Family Business Review, $27(4), 307-327$.

Kremer, H. M. (2006). Empresa familiar y mediación. Revista Interdisciplinaria de Mediación y Resolución de Conflictos, 1-5.

Lévi-Strauss, C. (1987). La estructura de los mitos. En Antropología estructural. Barcelona: Paidós. Lizaur, M. P. (2014). Las empresas familiares catalanas, chilenas y mexicanas: una comparación. Arxiu d'Etnografia de Catalunya, 14, 155-201.

Lozano Posso, M. y Urbano, M. (2008). La vinculación de descendientes a la empresa Familiar. Un estudio de casos colombianos. Estudios Gerenciales, 24(109), 37-63.

March, J. (1994). Ambigüedad e interpretación. Indianápolis: T. F. Press.

Martín, P. y Martínez, L. (2013). La gestión del conflicto en la Empresa Familiar como principio básico para su continuidad. En V. Fernández (ed.), Nuevas investigaciones sobre la gestión de la empresa familiar en España. Barcelona: OmniaScience.

Molina, A., Botero, S. \& Montoya, A. (2017). Estudios de rendimiento en las empresas de familia. Una nueva perspectiva. Estudios Gerenciales, 33(142), 76-86.

Morgan, G. (1991). Imágenes de la organización. Buenos Aires: Alfaomega.

Orozco, A. y Rentería, E. (2012) Empresa de familia: relaciones y conflictos en la transición generacional, una aproximación desde la psicología organizacional y del trabajo. Cali: Universidad de San Buenaventura.

Pacheco, A. (2015). Intervención organizacional: primeras aproximaciones conceptuales. Gestión y estrategia, 48, 15-24.

San Martín, J. M. y Durán, J. A. (2016). Sucesión y su relación con endeudamiento y desempeño en empresas familiares. Contaduría y Administración, 61(1), 41-57.

Sandoval, J. H. \& Guerrero, D. E. (2010). Family business in Colombia: Towards the construction of a commercial management model. Revista UDCA Actualidad y Divulgación Científica, 13(1), 135-146.

Schein, E. (1985). La cultura organizacional y el liderazgo. Una visión dinámica. Barcelona: Plaza y Janés. 
Smircich, L. (1983). Concepts of culture and organizational analysis. Administrative Science Quarterly, 28(3), 339-358.

Solano, A. I. (2010). Toma de decisiones gerenciales. Tecnología en Marcha, 16(3), 44-55.

Spradley, J. P. (1979). The ethnographic interview. Nueva York: Holt, Rinehart and Winston.

Stewart, A. (2012, mayo). Anthropology of family business: Ten desiderata. In Proceedings, United States Association for Small Business and Entrepreneurship, 27th Annual Conference

Sundaramurthy, C. (2008). Sustaining trust within family businesses. Family Business Review, 21(1), 89-102.

Trevinyo-Rodríguez, R. N. (2010). Empresas familiares: visión latinoamericana. Estructura, gestión, crecimiento y continuidad. México: Pearson Educación.

Turner, V. (1999). La selva de los símbolos: aspectos del ritual Ndembu. Madrid: Siglo XXI.

Van Gennep, A. (1960). The rites of passage. Londres: Routledge Library Editions.

Vieytes, R. (2004). Metodología de la investigación en organizaciones, mercado y sociedad: epistemología y técnicas. Buenos Aires: Editorial de las Ciencias.

Yin, R. K. (2009). Case Study Research: Design and Methods (Applied social research methods), $4^{\text {th }}$ ed. London \& Singapore: Sage Publications. 